\title{
Postvalvular enterocytes in feral and farm-reared sea bass Dicentrarchus labrax; hypervacuolization related to artificial feed
}

\author{
M. Deplano, R. Connes*, J. P. Diaz \\ Laboratoire de Biologie animale, Université de Montpellier II, Sciences et Techniques du Languedoc, F-34095 Montpellier \\ Cedex 5, France
}

\begin{abstract}
The postvalvular intestine of sea bass, which is involved in the absorption of protein macromolecules by pinocytosis, was studied by light microscopy, scanning electron microscopy and transmission electron microscopy. We describe the morphofunctional characteristics of this enteric region for control specimens from a natural environment. In comparison, we distinguished a disease affecting the intestine of farm-reared sea bass nourished with artificial feed. The disease is characterized by vacuolization and hypertrophy of enterocytes, combined with modifications of organelles (scarce mitochondrial cristae, enlarged elements of endoplasmic reticulum, pycnotic nucleus) and microvilli. It results in hypertrophy of intestinal folds and abrasion of degenerating epithelium. Observations of the intestine of farm-reared sea bass at different periods of the year showed that enterocyte vacuolization varies with season.
\end{abstract}

\section{INTRODUCTION}

A current problem in intensive fish breeding is the unsuitability of diets for the nutritional needs of adults and larvae, which can lead to intestinal diseases. Most such diseases have been studied in larvae. Epithelial dysplasia, hypertrophy, and necrosis were reported by Eckmann (1985) in the intestine of Coregonus sp. Cousin et al. (1986) detected atrophy and desquamation of intestinal epithelium in Scophthalmus maximus. Segner et al. (1987) reported Chlorella-induced cell damage in larval Chanos chanos resembling damage caused by fasting.

We have previously described (Deplano et al. 1989) the absorption of lipids in the proximal intestine of the immature sea bass Dicentrarchus labrax. Comparison of feral and farm-reared individuals revealed deterioration of the mucosa resulting in lipid overloading in enterocytes and intercellular spaces, mainly caused by artificial feed. The objective of the present study was to investigate another type of disease, also of dietary origin, which was observed in the distal intestine of the same individuals. We first studied the morphology and function of this segment of the intestine.

\footnotetext{
- Author for reprint requests
}

\section{MATERIALS AND METHODS}

Experimental conditions. Immature farm-reared sea bass less than 2 yr old (classes $0+$ and $1+$ ) were provided by the IFREMER center of Palavas (Hérault, France). They were raised in cages submerged in Prévost lagoon and given commercial artificial pellets distributed manually, containing fish meal $48 \%$, animal meals $15 \%$, cereals $22 \%$, fish oil $6 \%$, brewer's yeast $5 \%$, vitamins and minerals $4 \%$, water $10 \%$. Since the fish were raised in a lagoon, they were exposed to the large seasonal physicochemical variations of the natural environment, notably temperature (see Graph 1). The population of sea bass was observed for a whole annual cycle, from September 1985 to September 1986. Five individuals were sampled at random each month at the same hour. Variations in the feed ration are shown in Graph 1. Individual weights ranged from 34.5 to $167 \mathrm{~g}$ and sizes from 125 to $215 \mathrm{~mm}$.

The morphofunctional study of the postvalvular intestine was carried out on 15 individuals belonging to the same weight and size class, caught by angling in October and November 1985, several hundred meters from the experimental site. The temperature was high enough at this time to assure adequate nourishment of the fish, both in captivity and in the natural environ- 


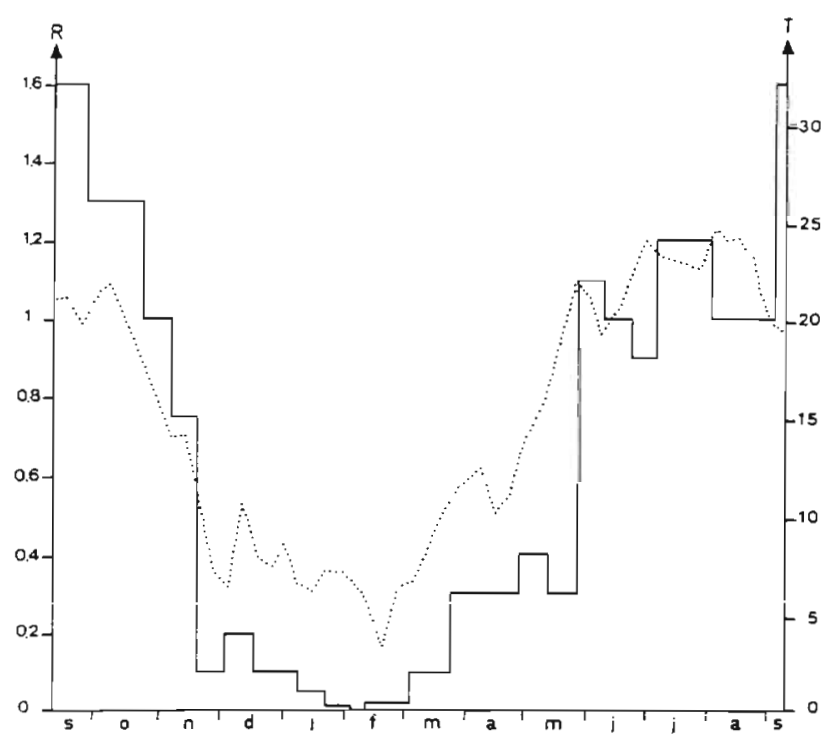

Graph 1. Variations of temperature (T) and feed ration (R) during the 1985-1986 experiments. Information from the zootechnical staff at IFREMER, Palavas. (…) Temperature $\left({ }^{\circ} \mathrm{C}\right) ;(-)$ feed ration (\% of biomass)

ment. Five individuals, whose digestive tracts were filled with shrimp and fish when they were caught, were used to characterize the condition of the intestinal epithelium just after feeding. Five others were fasted for a week and used to determine the structure of 'resting' enterocytes. The last 5 were studied for ferritin absorption. Photographs showing the condition of feral fish were obtained from these 15 specimens. We also used 2 further groups of fish of different origins as control specimens. The first were farm-reared sea bass of classes $0+$ and $1+$ fed on fresh fish paste in an experiment comparing several types of feed. All the fish died during the exceptional cold wave in January 1985 and the results were too fragmentary to be published. However, sampling was carried out every month from August 1984 to January 1985. The second group consisted of sea bass of different ages caught by trawling from the oceanographic boat 'Georges Petit' on the continental shelf of the Mediterranean Sea between Sète and Palavas in May, July, and October 1984, May and October 1985, February 1986, and April 1987. Intestinal fragments intended for other studies were dissected from several individuals on each of these trips and subjected to histological examination

Fish were decapitated and dissected immediately (12 h after last feed for reared specimens). Intestinal fragments were removed $1 \mathrm{~cm}$ distal to the valvula.

Light microscopy. Samples were fixed in Bouin's fluid for 24 to $48 \mathrm{~h}$ at room temperature, dehydrated in ethanol and embedded in paraffin. Sections attached to slides were stained with Masson trichrome and mounted in synthetic resin. The PAS technique was used to detect polysaccharides of mucocytes

Absorption and detection of ferritin. One milliliter of a $10 \mathrm{mg} \mathrm{ml}^{-1}$ ferritin solution was administered anally or orally to 5 feral sea bass and the fish were killed $14 \mathrm{~h}$ later. Their intestines were removed and treated with Prussian blue (Perls) before being fixed with Bouin's fluid. Section contrast was enhanced by staining the base with naphthol yellow and solid nuclear red.

Acid phosphatase detection. Intestinal fragments fixed with $2.5 \%$ glutaraldehyde $(350 \mathrm{mOsm})$ for $1 \mathrm{~h}$ at $4{ }^{\circ} \mathrm{C}$ were rinsed abundantly $(6 \times 10 \mathrm{~min})$ with sodium cacodylate $(0.175 \mathrm{M}, \mathrm{pH} 7.2)$ and embedded in $20 \%$ gelatin. The blocks were trimmed, frozen in liquid nitrogen, and sectioned on a Reichert-Jung 2700 cryostat. Enzyme activity was detected by the azo method of Burstone (1958) with incubation for $3 \mathrm{~h}$. The salt of 'Fast Violet LB' diazonium was used, which gives a red stain.

Scanning electron microscopy (SEM). Samples were subjected to double fixation with $2.5 \%$ glutaraldehyde (350 $\mathrm{mOsm})$ for $1 \mathrm{~h}$ and with $1 \%$ osmium tetroxide $[350$ mOsm) for $1 \mathrm{~h}$, buffered with sodium cacodylate ( $\mathrm{pH}$ 7.2). After dehydration in a graded series of alcohol, samples were dried by the critical point method, metallized, and observed with a Jeol JSM 35 microscope.

Transmission electron microscopy (TEM). Following fixation and dehydration (see above), samples were embedded in Epon 812 and sections were cut with an LKB ultramicrotome. Contrasting was performed with uranyl acetate $(1 / 2 \mathrm{~h})$ and bismuth subnitrate $(1 / 2 \mathrm{~h})$, except for samples subjected to the ferritin absorption test. Sections were observed with a Jeol 200 CX microscope.

\section{RESULTS}

The sea bass intestine comprises 2 distinct regions separated by a valvula, i.e. the proximal or prevalvular intestine (about $80 \%$ of the total length), which has 5 caeca, and the distal or postvalvular intestine (about $20 \%$ of the total length).

\section{Postvalvular intestine of feral sea bass}

\section{Structure}

Under SEM, the postvalvular intestine was seen to have single folds oriented longitudinally and linked to one another by many complex anastomoses (Fig. 1). The microvilli formed a solid surface cover, penetrated frequently by mucocyte orifices.

The wall of this terminal region differed slightly from that of the prevalvular intestine (Deplano et al. 1989). 
The muscularis was larger, consisting of a very thick layer of circular fibers between 2 thinner layers of longitudinal fibers. The internal fibers came into contact with a dense connective tissue layer of constant thickness, the stratum compactum, which contained sparse venules and arterioles. These vessels were more frequently seen in the underlying muscularis, where they gave off thin ramifications to the mucosa (Fig. 2). The latter was composed of loose, abundant connective tissue, the lamina propria, and a single prismatic epithelium. Mucocytes were larger and more numerous here than in the prevalvular intestine. The supranuclear cytoplasm of the enterocytes was only slightly stained, and contained many small vacuoles (Fig. 3).

In postvalvular enterocytes of the fasting fish, invaginations penetrated the apical cytoplasm between the bases of microvilli. The latter were 2.5 to $3 \mu \mathrm{m}$ long and were supported by microfilaments that sank deep into the apical cytoplasm. This zone was occupied by an elaborate system of tubules and vesicles mainly arising from the invaginations. Below this was an extensive region containing vacuoles of different sizes $(0.3$ to $1.2 \mu \mathrm{m})$ that enclosed electron-dense granular material and smaller dense bodies $(0.2$ to $0.6 \mu \mathrm{m})$. The vacuoles and dense bodies often contained variably compact coils of membrane material or pseudomyelin structures. This region also comprised several spherical or elongated mitochondria and endoplasmic reticulum (Fig. 4). The same organelles were found in the nuclear region and in the basal portion of the cell, where they were particularly abundant. The Golgi apparatus, consisting of several dictyosomes, was located in the supranuclear region. Lamellar structures, which were particularly developed at the basal pole of the cell, were also abundant in other regions, except in the apical zone occupied by the tubulovesicular system.

The epithelium of the postvalvular intestine showed strong acid phosphatase activity in the apical region of the enterocytes, marked by a wide dark band. The reaction was more intense and widespread than in the prevalvular intestine. Positive elements were also observed at the base of cells and in the lamina propria (Fig. 5).

\section{Absorption of protein macromolecules}

After a feed consisting mostly of small shrimp, amphipods, and fish, the apical vacuoles of the postvalvular enterocytes increased in number and size, and contained material of variable density. These vacuoles occasionally fused to form bulkier elements not more than $2.5 \mu \mathrm{m}$ in diameter in most of the absorbing cells (Fig. 6). However, in several cells at the top of the folds, this fusion phenomenon produced a large spherical vacuole sometimes reaching $5 \mu \mathrm{m}$ in diameter. All enterocytes observed in feral fish had the same appearance regardless of the season or the age of the individual. The only variation concerned the size and abundance of apical vacuoles, which were larger and more numerous in fish whose digestive tract was filled with prey undergoing digestion.

When ferritin was introduced orally or anally into the digestive tract, the postvalvular intestinal folds were stained brown, which is characteristic of this iron-rich protein complex. The Prussian blue reaction carried out immediately on the whole intestine confirmed the presence of iron in the postvalvular mucosa, which was stained very bright blue from the valvula to the anus.

On histological sections, the presence of blue granules in the supranuclear region of enterocytes confirmed the involvement of these cells in ferritin absorption. The granules were particularly abundant at the tops of the folds (Fig. 7) and decreased gradually until they disappeared completely at the base.

Under TEM, ferritin could be seen in the form of granules that were contrasted in pinocytotic vesicles and tubules and in large quantities in apical vacuoles showing uneven contours or subspherical forms (Fig. 8). Connections between pinocytotic tubules and vacuoles were sometimes visible. The latter occasionally fused. Some of them containing mostly ferritin had a contrasted and homogeneous appearance. Others had a heterogeneous appearance and contained isolated dark areas of ferritin within clearer material.

\section{Postvalvular intestine of farm-reared sea bass}

\section{Vacuolization and hypertrophy of enterocytes}

The postvalvular enterocytes of the farm-reared fish quite often showed severe hypertrophy due to abnormal development of a large supranuclear vacuole. In extreme cases observed in September 1985 (Figs. 9 to 12), the vacuole occupied almost the entire cell, pushing the nucleus and a small portion of cytoplasm towards the base (Fig. 9). This pathological state occurred at various locations on the folds but was always most severe near the top. Enterocyte hypertrophy produced enlargement of the folds, which were often much higher and wider than in feral fish (Fig. 13). The mucous cells showed no change in number or structure. They had a basal nucleus, above which was a very active Golgi apparatus producing many grains of PAS + mucigen.

On TEM images (Fig. 10), the apical membrane of hypertrophied enterocytes often bulged, and this deformation was accompanied by an uneven implantation of microvilli. Apical invaginations were scarce and not very deep. The underlying cytoplasm showed abun- 

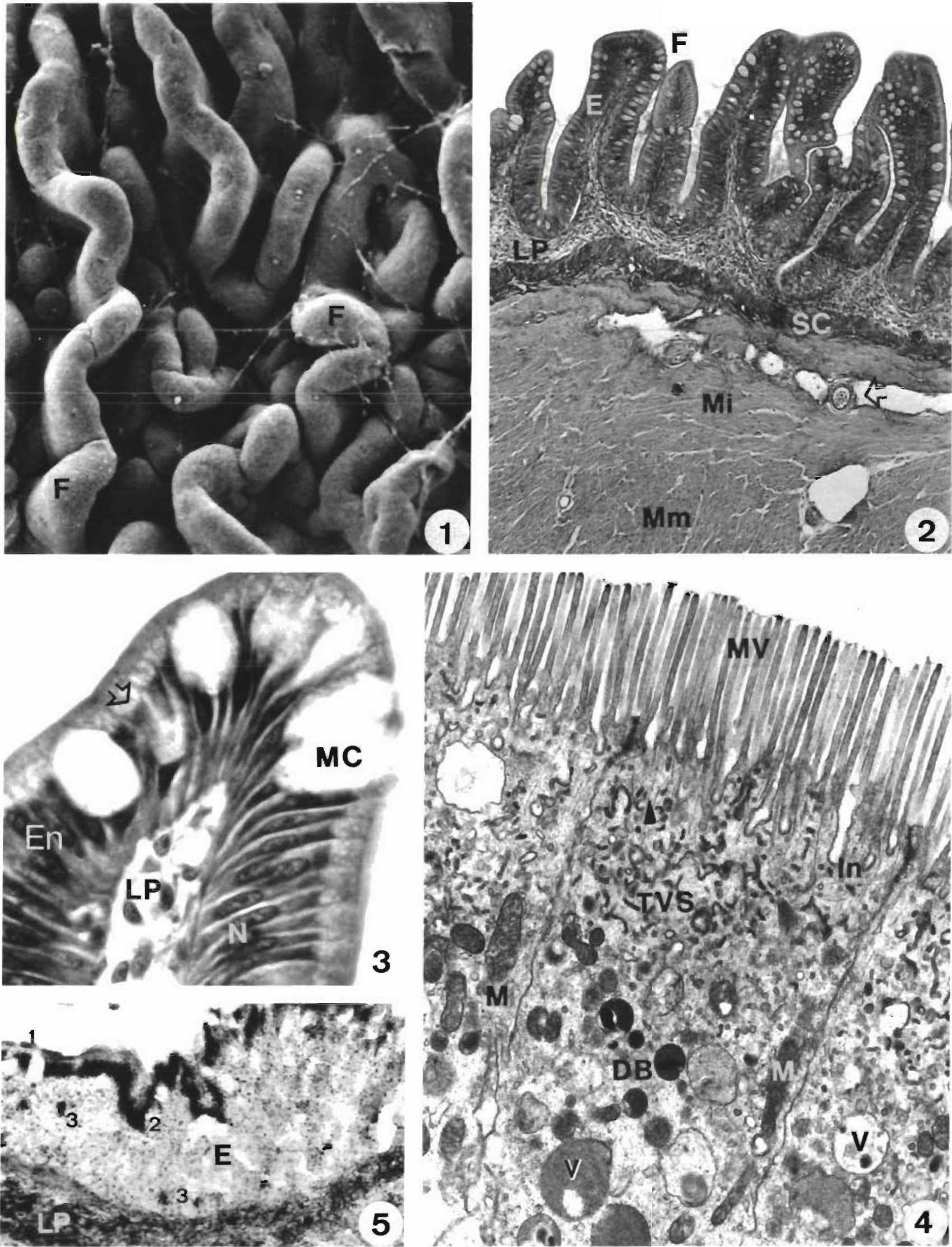

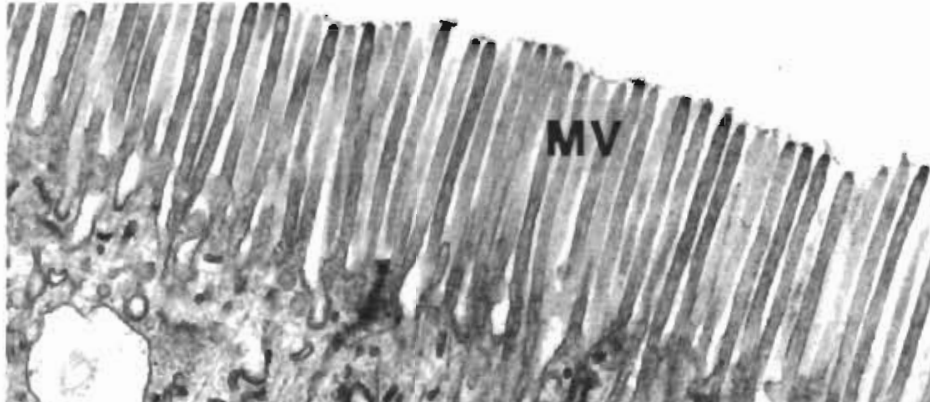

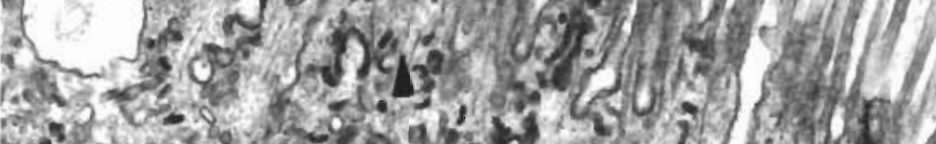

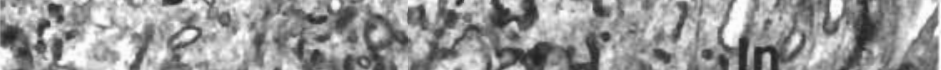

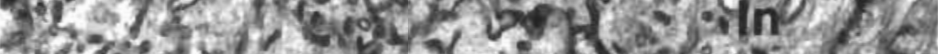

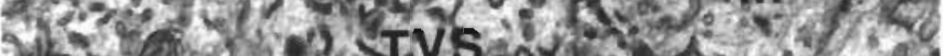

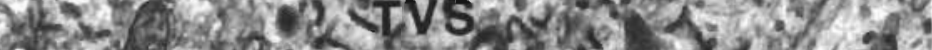

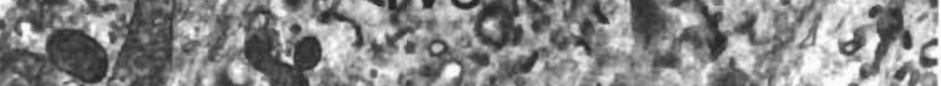

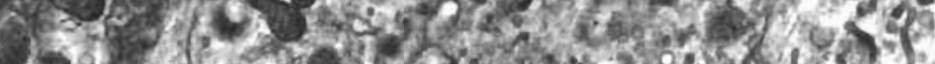

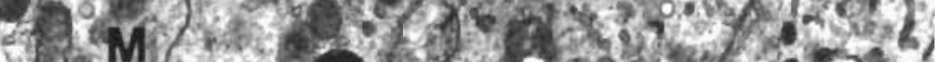

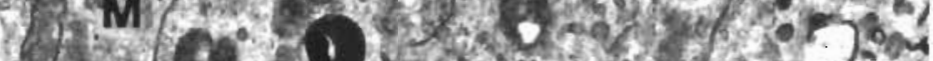

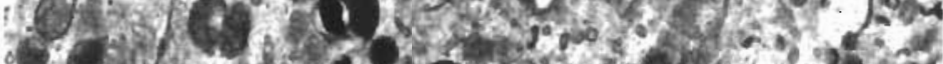

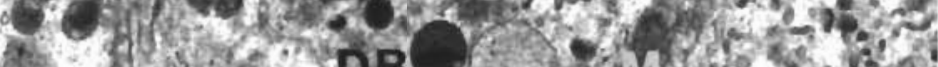

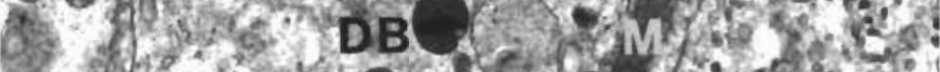

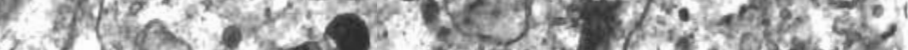

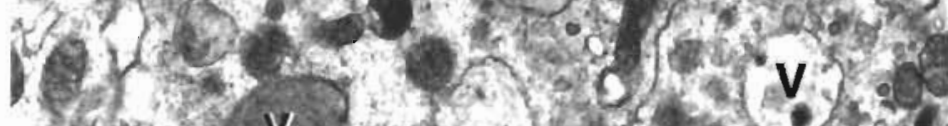

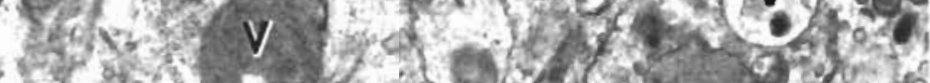

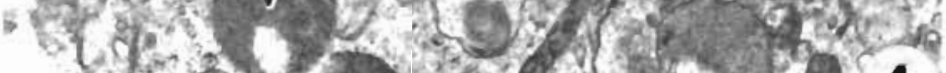

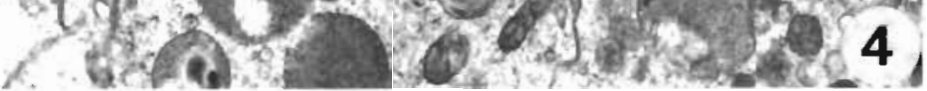


Figs. 1 to 5. Dicentrarchus labrax. Postvalvular intestine of feral sea bass Fig. 1 SEM view of the intestinal surface the folds (F) are single and anastomosed. $(\times 110)$. Fig 2 Histological section of the intestınal wall The epıthelıum (E) lies on the lamina propria (LP). The stratum compactum (SC) has a constant thickness. Arterioles, venules, and lymphatıc vessels (arrow) can be seen in the internal muscular layer (Mi). Mm: middle muscular layer; F fold $(\times 115)$ Fig 3 Higher magnification of the epithelium The supranuclear cytoplasm of the enterocytes (En) is only slightly stamed and contanns small vacuoles (arrow). N. nucleus, MC mucous cell; LP: lamina propria. $(\times 1350)$. Fig. 4. TEM view of the upper region of an enterocyte in a tasting sea bass. The microvilli (MV) are supported by microfilaments that penetrate the apical cytoplasm (arrowhead) containing the tubulovesicular system (TVS). Vacuoles (V) and dense bodies (DB) are present In invagnation, $M$ mitochondna. $(\times 10000)$. Fig. 5 . Detection of acid phosphatase in the postvalvular mucosa The enzyme activity is localized in the striated border (1), apical cytoplasm (2), and dense bodies (3) The lamina propria (LP) also shows strong reactivity $(\times 430)$

dant pinocytotic vesicles, but few tubules. The vesicles fused with vacuoles of different sizes $(0.5$ to $5 \mu \mathrm{m})$ which in turn fused with the giant supranuclear vacuole. This cavity was uniformly clear in most enterocytes, but in some cells it enclosed clusters of electrondense material that were more or less evenly distrbuted and occasionally surrounded by a less contrasted substance. As the vacuole developed, it pushed back the cytoplasm around it, thereby causing protrusion of the apical membrane into the intestinal lumen and bending of adjacent cells. It pushed the nucleus and perinuclear cytoplasm towards the base, deforming the basal lamina, which became convex on the outside. At maximum hypertrophy, the vacuole sometimes reached a height of $40 \mu \mathrm{m}$ and a width of $20 \mu \mathrm{m}$. At this point the highly deformed enterocyte was in the process of degeneration: cytoplasm was scarce, the brushborder was disorganuzed (Fig 11) or absent, the organelles had deternorated considerably, there were fewer mitochondrial cristae, the endoplasmic retıculum
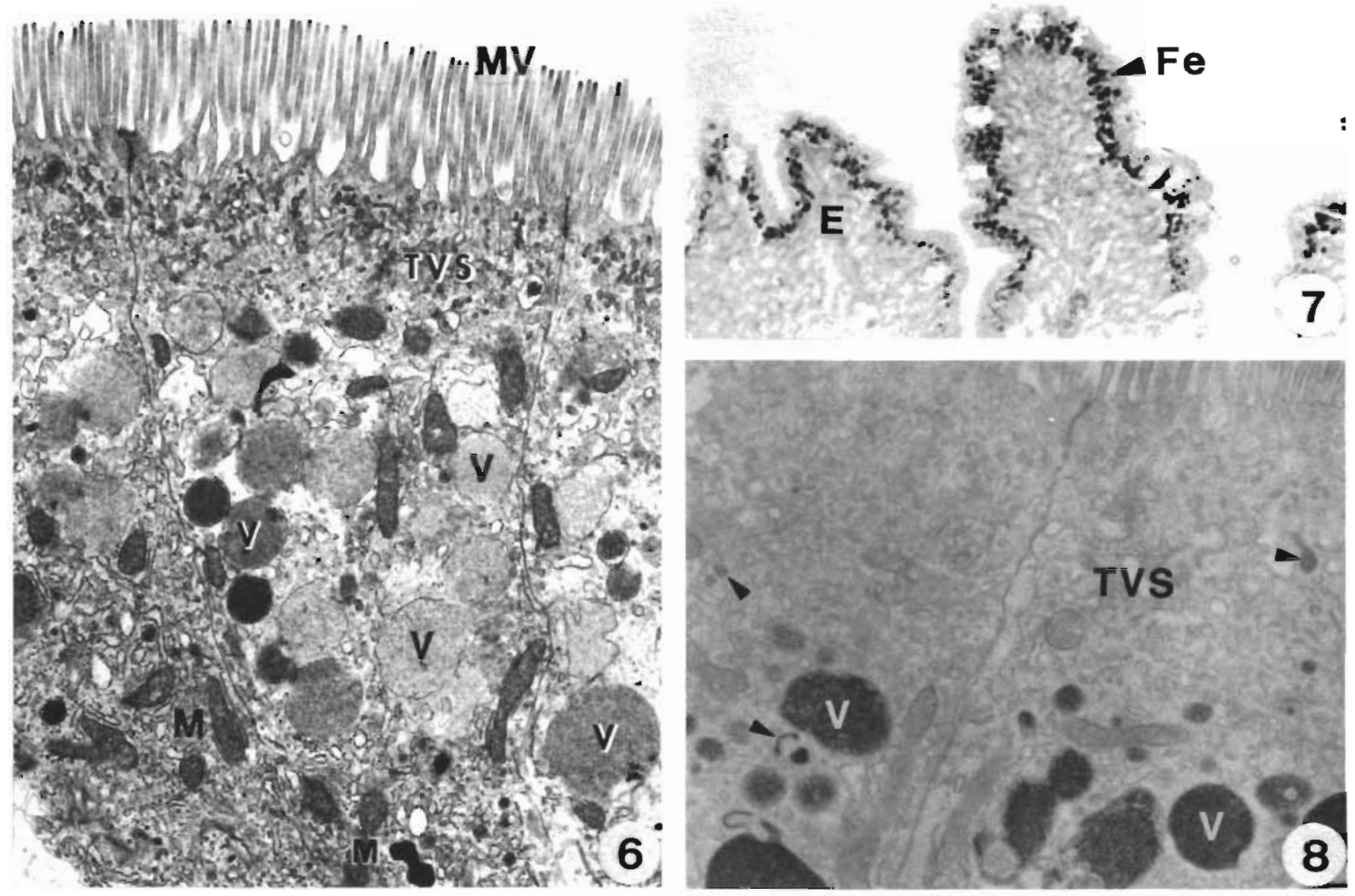

Figs. 6 to 8. Dicentrarchus labrax. Postvalvular intestine of feral sea bass (continued) Frg. 6. Ultrastructure of a postvalvular enterocyte after feeding. The apical pole of the cell contans many small supranuclear vacuoles (V) MV. microvilli; TVS tubulovesicular system; M: mitochondria ( $\times 7700)$ Fig. 7 Epithelium (E) stamed with Prussian blue after ferritın absorption Dark grains of ferritin ( $\mathrm{Fe}$ ) can be seen in the apical portıon of the enterocytes $(\times 640)$ Fig. 8. Ultrastructure of the apex of an enterocyte absorbing ferritin. The protein is visible in the apical pinocytotic vesicles and tubules (arrowhead) as well as in the supranuclear vacuoles (V) which accumulate it TVS tubulovesıcular system $(\times 8800)$ 

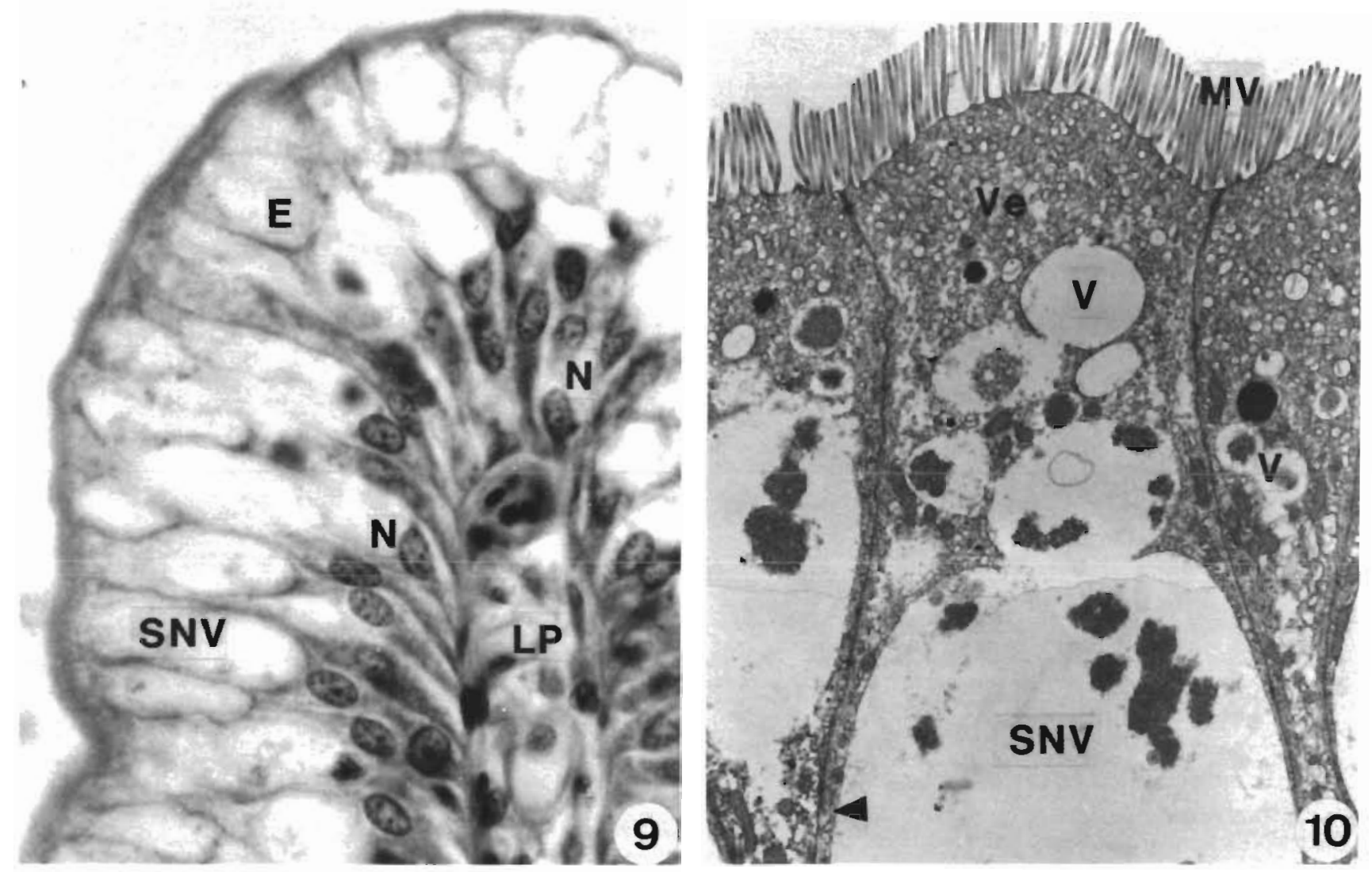

Figs. 9 \& 10. Dicentrarchus labrax. Postvalvular intestine of farm-reared sea bass. Fig. 9. Light microscopic view of the degenerated mucosa in September 1985. The hypertrophied enterocytes have a giant supranuclear vacuole (SNV). The nuclei (N) are pushed toward the base of the cells. E: epithelium; LP: lamina propria. $(\times 1450)$. Fig. 10. Fine structure of the apical region of an enterocyte in September 1985. Note the uneven implantation of microvilli (MV), the bulging form of the apical membrane, and the absence of tubules. Many vesicles (Ve) combine to form vacuoles (V) that fuse into a very clear supranuclear vacuole (SNV) As this vacuole develops, it pushes back the cytoplasm, which eventually only forms a thin band against the lateral membrane (arrowhead). ( $\times 6000)$

elements were enlarged, and the nucleus was pycnotic. The cell was eventually extruded into the intestinal lumen.

The intestinal surface was highly disturbed by this enterocytic transformation. The hypertrophic folds were less distinct than in feral fish, since they were separated by smaller spaces. The degeneration of many enterocytes produced orifices on the surface and occasionally even abrasion of the epithelium (Fig. 12). Farm-reared fish fed with fish paste during 1984-1985 showed no detectable cytological changes in their postvalvular epithelium.

Variation of disease with season

In the present report, we describe the general pattern of enterocyte vacuolization depending on the season (Graph 1: temperature variations). Detailed monitoring of the condition of the intestinal mucosa will be reported in a subsequent article (Deplano et al. 1991).

Figs. 11 to 15. Dicentrarchus labrax. Postvalvular intestine of farm-reared sea bass (continued). Fig. 11. Extreme hypertrophy of an enterocyte in September 1985. Note the very distinct cell deformation and the small quantity of cytoplasm between the supranuclear vacuole (SNV) and the lateral plasma membrane (arrowhead). MV: microvilli. ( $\times 4000$ ). Fig. 12. Surface of vacuolized epithelium in September 1985. The folds (F) show pronounced hypertrophy and their boundaries are not very clear The destruction of numerous cells produces orifices (O). Abrasion zones have started to form (arrow). ( $\times 430)$. Figs. 13 to 15. Seasonal variation of epithelial vacuolization. $(\times 110)$. Fig 13: Sample of Semptember $1985\left(\mathrm{~T}=21^{\circ} \mathrm{C}\right)$. Vacuolization of the epithelium (E) starts at the base (arrowhead) of the folds $(F)$, which show very clear hypertrophy and a highly stretched lamina propria (LP). Fig. 14: Sample of December $1985\left(\mathrm{~T}=7.5^{\circ} \mathrm{C}\right)$. Vacuolization of the epithelium only involves the upper half (arrowhead) of the folds. Hypertrophy is less pronounced than in the sample of September 1985 (Fig. 13). Fig. 15: Condition of the mucosa in May $1986\left(\mathrm{~T}=18.5^{\circ} \mathrm{C}\right)$. The structure is quite comparable to that of the controls 

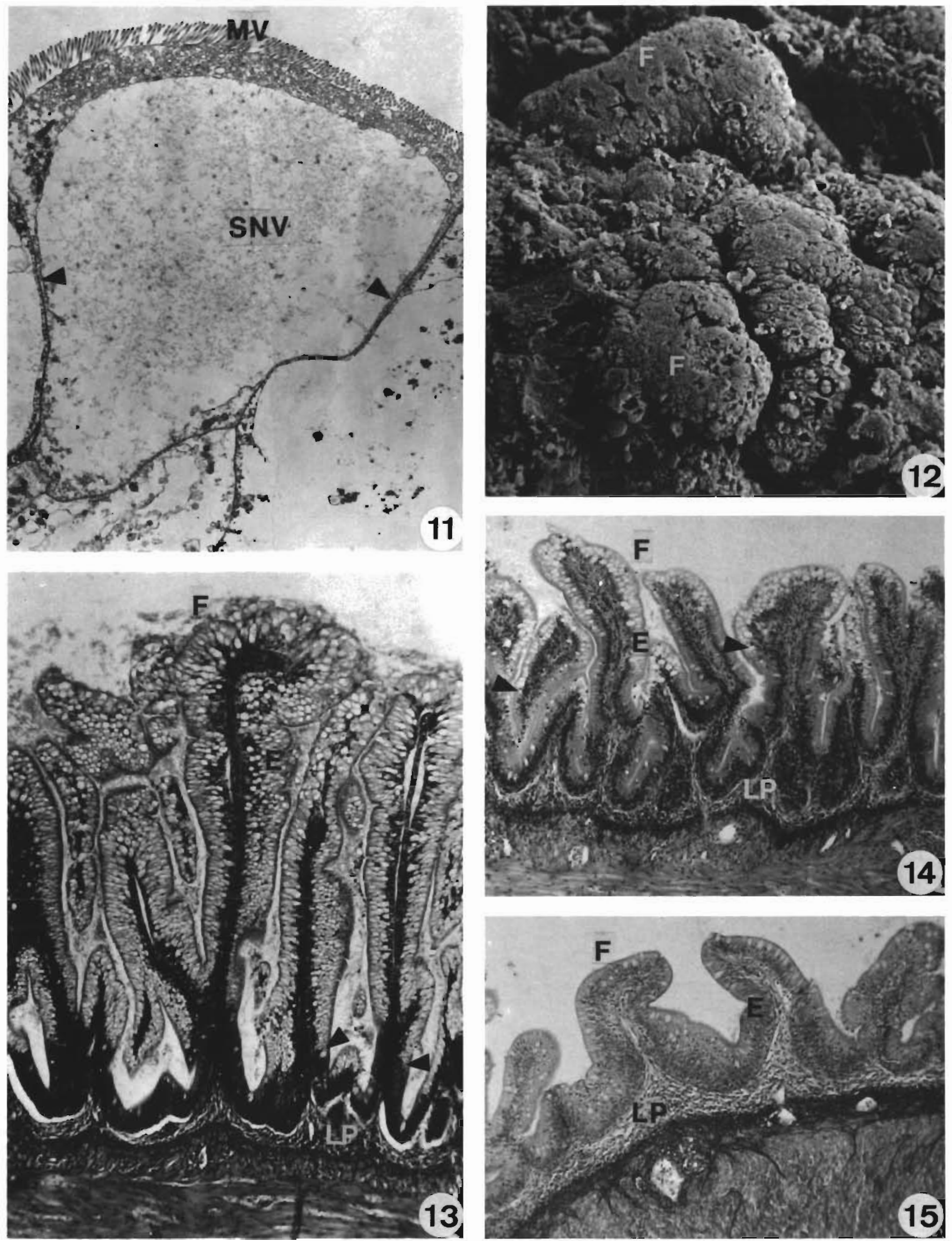
Starting with the maximum in September 1985 (Fig. 13), enterocyte vacuolization gradually decreased as temperatures fell in autumn and winter (Fig. 14). The decrease continued until the end of March, i.e. after the minimal temperatures in February 1986. The vacuolization rate remained very low between the end of March and the middle of May (Fig. 15) while temperatures rose above the threshold at which sea bass resume feeding $\left(7^{\circ} \mathrm{C}\right)$. Between May and June, vacuolization was strongly reactivated. It increased more slowly until September 1986, when deterioration was practically as severe as in September 1985.

No other pathological signs were observed in farmreared fish and despite their deteriorated mucosa, they showed satisfactory weight increase $(134 \%)$ between May and September, with a mortality of $7.4 \%$. Mortality then reached $29.4 \%$ in the short period between November 20 and December 4, 1985 when the temperature dropped from 12 to $7^{\circ} \mathrm{C}$.

\section{DISCUSSION}

\section{Postvalvular enterocytes and macromolecule absorption in feral sea bass}

The postvalvular enterocytes of the feral sea bass showed deep invaginations between microvilli, giving rise to pinocytotic vesicles, an elaborate tubulovesicular network, a vacuolar system, and a large array of microfilaments and microtubules providing cohesion and mobility. This organization of the apical region is completely compatible with the absorption of protein complexes such as ferritin. When administered anally, this molecule does not undergo gastric digestion and is absorbed intact. The presence of ferritin in different cellular compartments indicates the pathway generally described for the ingestion of protein markers (ferritin and particularly horseradish peroxidase) in freshwater teleosts, i.e. the proteins are incorporated into pinocytotic vesicles and tubules and are transported to supranuclear vacuoles where they accumulate (Gauthier \& Landis 1972, Noaillac-Depeyre \& Gas 1973, 1976, 1979, 1983, Stroband \& van der Veen 1981). The same cellular organization and function have been described in the ileum of newborn mammals (Clark 1959, Graney 1968). In both mammals and fishes, these vacuoles are frequently considered to be secondary lysosomes or phagolysosomes, in which ingested proteins undergo enzymatic degradation. This hypothesis is supported by the presence of several hydrolases in the supranuclear bodies of the rat (Cornell \& Padykula 1969). According to Ono \& Satoh (1981) and Gonnella \& Neutra (1984), the presence of acid phosphatase in the supranuclear vacuoles of newborn rat enterocytes indicates that these structures are phagolysosomes, since this enzyme is one of the most characteristic of lysosomal systems. In the second segment of the goldfish intestine, Gauthier \& Landis (1972) detected strong acid phosphatase activity similar to that observed in the sea bass. The trout has 2 additional lysosomal proteases, cathepsins B and D, in the vacuolar system of posterior epitheliocytes (Georgopoulou et al. 1986). Thus, this region in fishes contains the enzymatic machinery capable of degrading ingested proteins. It can be assumed that these enzymes originate from primary lysosomes produced by the Golgi apparatus, which fuse with the supranuclear vacuoles. Consequently, the hypothesis proposed by Watanabe (1984b) for Cottus nozawae can be applied to be sea bass.

Most authors claim that the role of this intestinal segment in nutrition is to complement insufficient intraluminal protein digestion. This function must be particularly important in the adult cyprinids Carassius auratus, Cyprinus carpio, Tinca tinca, and Ctenopharyngodon idella, studied by Gauthier \& Landis (1972), Noaillac-Depeyre \& Gas (1973, 1976), and Stroband \& van der Veen (1981), respectively, since these species have no stomach or pepsin activity. The fusion of enterocytic vacuoles into bulky supranuclear bodies, as in newborn mammals, suggests large capacities for absorption. The presence of a stomach in Perca fluviatilis, Oncorhynchus mykiss, Ameiurus nebulosus, and Girella tricuspidata does not preclude the absorption of intact proteins in the adult, as shown by the observations of Noaillac-Depeyre \& Gas (1979), Ezeasor \& Stokoe (1981), Noaillac-Depeyre \& Gas (1983), and Anderson (1986). We have observed the same phenomenon in Dicentrarchus labrax: nondegraded ferritin was completely absorbed in specimens $30 \mathrm{~cm}$ long. In contrast, the observations of the authors mentioned above lead us to assume that in species having a stomach, the enterocytic vacuoles may be smaller, and although they may fuse, they do not form large supranuclear bodies. Thus, the formation of this large vacuole in agastric species indicates a greater capacity for endocytosis, perhaps in relation to less effective intraluminal digestion. It should be noted that in young mammals the capacity to ingest protein macromolecules arises before the appearance of pepsin activity and disappears 2 or 3 wk after birth when the stomach becomes functional (Graney 1968). Similarly, in the teleosteans Oncorhynchus masou, Hypomesus transpacificus nipponensis and Chaenogobius annularis, horseradish peroxidase can be absorbed by larvae and juveniles, but the capacity progressively decreases after the appearance of gastric function, and disappears entirely in the adult (Watanabe 1984a, c, Watanabe \& Sawada 1985). 
Adult teleosts can thus be classified in 3 categories according to the endocytotic capacities of the enterocytes in the intestinal segment responsible for macromolecule absorption: (1) species without a stomach, which show a strong capacity for absorption, (2) species with a stomach, showing less capacity for absorption, and (3) species with a stomach, showing no absorption. The sea bass fulls into the second category.

The extent of intraenterocytic protein digestion is not very well known in fishes. According to Stroband \& van der Veen (1981), it is meager even in agastric species, but can be preponderant under unfavorable physiological conditions. Ezeasor \& Stokoe (1981) consider that intracellular digestion plays a complementary role in the case of an overabundant feed.

The property of absorbing nondegraded molecules by endocytosis has given rise to an interesting though limited application in the field of immunization against infectious diseases. Many authors have mentioned the possible function of the posterior intestine in immunological phenomena (Rombout \& van den Berg 1985. McLean \& Ash 1987, Georgopoulou et al. 1988, Rombout et al. $1989 \mathrm{a}$, b). Antibacterial vaccination via the digestive route produces less stress than other methods and has yielded conclusive results in cyprinids (Davina et al. 1982) and salmonids (Johnson \& Amend 1983).

\section{Vacuolization and hypertrophy of postvalvular enterocytes in farm-reared sea bass}

This disease, which has not been reported in the literature, is characterized by the overdevelopment of the supranuclear vacuolar system in enterocytes. It results in the formation of giant vacuoles causing cytological deterioration combined with cell degeneration and pronounced epithelial abrasion. These symptoms are undoubtedly linked to the inadequacy of artificial diet, based on the following data: (1) at the beginning of autumn, when farm-reared sea bass were still affected by a marked hypervacuolization, feral specimens of the same age taken from a similar biotope showed a healthy mucosa even though they were feeding abundantly, as shown by their digestive tract contents; (2) feral fish of different ages captured on the coast between Sète and Palavas in February, April, May, July and October, i.e. under cold and warm conditions, never showed these enterocyte modifications; (3) during a brief period (August 1984 to Januar 1985), Dicentrarchus labrax fed on fresh fish had a normal postvalvular intestine, whereas the intestine of artificially fed individuals deteriorated considerably.

The giant vacuoles observed here may have resulted from the excess of undigested proteins in the postvalvular intestine, which could have been caused by sev- eral factors: (1) an excessive proportion of proteins in the feed ration, (2) partial or total indigestibility of some proteins by gastric or pancreatic enzymes, (3) a qualitative or quantitative deficit of intraluminal proteolytic agents. Enterocytes that are overburdened with absorption and intracellular digestion probably age more quickly than those in feral fish, and the lysosomal system may begin to show functional lethargy. This could then lead to the appearance of bulky secondary lysosomes causing hypertrophy and extrusion of the cells producing them.

The putative lysosomal dysfunction may also be related to the nondegradable or toxic character of the macromolecules absorbed in the postvalvular intestine. The giant vacuoles may contain an excess of acid hydrolases that cause varying degrees of injury to adjacent enterocytes when they burst. The rejection of some enterocytes and the deterioration of others by the release of hydrolases may at least partially explain this disease of the postvalvular intestine, which can become severe when $80 \%$ of the epitheliocytes are affected by hypervacuolization.

The degree of deterioration in the postvalvular mucosa was found to vary according to the season. It was greatest in the warm seasons, when the fish feed abundantly. In summer, this pathology was well tolerated by the sea bass population, which showed large growth $(134 \%)$ and low mortality $(7.4 \%)$. They feed very little during the winter, and not at all when the temperature falls below $7{ }^{\circ} \mathrm{C}$. Deterioration was slight or absent at this time, indicating epithelial healing.

Farm-reared sea bass undergo the first temperature fall with a disorganized postvalvular epithelium, which can favor hemorrhages, infections, and immune reactions. This may explain the high mortality (nearly $30 \%$ ) observed at the end of autumn 1985, when the temperature dropped from 12 to $7^{\circ} \mathrm{C}$. According to some physicians ( $\mathrm{C}$. Cohen pers. comm.) the abnormal transit of proteins into the internal milieu can have deleterious effects on human consumers of fish. Complementary research on fish feed that is quantitatively and qualitatively balanced should make it possible to overcome these problems quite quickly.

Acknowledgements. We thank the personnel of the IFREMER station of Palavas, who provided us with numerous fish and zootechnical informations. We are indebted to Mr T. Noell and to the personnel of electron microscopic laboratory, especially Mr J. P. Selzner, for their excellent technical assistance.

\section{LITERATURE CITED}

Anderson, T A. (1986). Histological and cytological structure of the gastrointestinal tract of the luderick, Girella tricuspidata (Pisces, Kyphosidae), in relation to diet. J. Morphol. 190: $109-119$ 
Clark, S. L. Jr (1959). The ingestion of proteins and other colloidal materials by columnar absorptive cells of the small intestune in suckling rats and mice. J. biophys. biochem. Cytol. 5: 41-50

Cornell, R., Padykula, H. A. (1969). A cytological study of intestinal absorption in the suckling rat. Am. J. Anat. 125: 291-316

Cousin, J. C. B., Balouet, G., Baudin-Laurencin, F. (1986) Altérations histologiques observées chez les larves de turbot (Scophthalmus maximus L.) en élevage intensif Aquaculture 52: 173-189

Davina, J. H. M., Parmentier, H. K., Timmermans, L. P. M. (1982). Effect of oral administration of Vibrio bacterin on the intestine of cyprinid fish. Dev. Comp. Immunol. Suppl 2: $157-166$

Deplano, M., Connes, R., Diaz, J. P. (1991). Deux types de pathologie intestinale d'origine nutritionelle chez le Loup (Dicentrarchus labrax) en ćlevage et leur évolution en fonction des saisons. Rec. Méd. vétér. Ec. Alfort 167 (1) (in press)

Deplano, M., Connes, R., Diaz, J. P., Paris, J. (1989). Intestinal steatosis in the farm-reared sea-bass, Dicentrarchus labrax. Dis. aquat. Org. 6: 121-130

Eckmann, R. (1985). Histopathological alterations in the intestine of whitefish (Coregonus sp.) larvae reared on zooplankton from Lake Constance. Dis. aquat. Org. 1: 11-17

Ezeasor, D. N., Stokoe, W. M. (1981). Light and electron microscopic studies on the absorptive cells of the intestine, caeca and rectum of the adult rainbow trout, Salmo gairdneri, Rich. J. Fish Biol. 18: 527-544

Gauthier, G. F., Landis, S. C. (1972). The relationship of ultrastructural and cytochemical features to absorption activity in the goldfish intestine. Anat. Rec. 172: 675-702

Georgopoulou, U., Sire, M. F., Vernier, J. M. (1986). Immunological demonstration of intestinal absorption and digestion of protein macromolecules in the trout (Salmo gairdneri). Cell. Tissue Res. 245: 387-395

Georgopoulou, U., Dabrowski, K., Sire, M. F., Vernier, J. M. (1988). Absorption of intact proteins by the intestinal epithelium of trout, Salmo gairdneri. A luminescence enzyme immunoassay and cytochemical study. Cell. Tissue Res. 251. 145-152

Gonnella, P. A., Neutra, M. R. (1984). Membrane-bound and fluid-phase macromolecules enter separate prelysosomal compartments in absorptive cells of suckling rat ileum. J. Cell. Biol. 99: 909-917

Graney, D. O. (1968). The uptake of ferritin by ileal absorptive cells in suckling rats. An electron microscopic study. Am. J. Anat. 123: 227-254

Johnson, K. A., Amend, D. F. (1983). Efficacy of Vibrio anguillarum and Yersinia bacterins applied by oral and anal intubation of salmonids. J. Fish. Dis. 6: 473-476

McLean, E., Ash, R. (1987). Intact protein (antigen) absorption in fishes: mechanism and physiological significance. J. Fish Biol. 31 (Suppl. A): 219-223

Responsible Subject Editor: G. Peters, Hamburg, Germany
Noaillac-Depeyre, J., Gas, N (1973). Absorption of protein macromolecules by the enterocytes of the carp (Cyprinus carpio L.). Ultrastructural and cytochemical study. Z. Zellforsch. 146: 525-541

Noaillac-Depeyre, J., Gas, N. (1976). Electron microscopy study on gut epithelium of the tench (Tinca tinca L.) with respect to its absorptive functions. Tissue Cell. 8: 511-530

Noaillac-Depeyre, J., Gas, N. (1979). Structure and function of the intestinal epithelial cells in the perch (Perca fluviatilis L.). Anat. Rec. 195: 621-640

Noaillac-Depeyre, J., Gas, N. (1983). Etude cytophysiologique de l'épithélium intestinal du poisson chat (Ameiurus nebulosus L.). Can. J. Zool. 61: 2556-2573

Ono, K., Satoh, Y (1981). Uitrastructural localization of acid phosphatase activity in the small intestinal absorptive cells of postnatal rats. Histochemistry $71: 501-512$

Rombout, J. H. W. M., Lamers, C. H. J., Helfrich, M. H. Dekker, A., Taverne-Thiole, J. J. (1985). Uptake and transport of intact macromolecules in the intestinal epithelium of carp (Cyprinus carpio L.) and the possible immunological implications. Cell Tissue Res. 239: 519-530

Rombout, J. H. W. M., van den Berg, A. A. (1985). Immunological importance of the second gut segment of carp. I Uptake and processing of antigens by epithelial cells and macrophages. J. Fish Biol. 35: 13-22

Rombout, J. H. W. M., Bot, H. E., Taverne-Thiele, J. J. (1989a) Immunological importance of the second gut segment of carp. II. Characterization of mucosal leucocytes. J. Fish Biol. 35: 167-168

Rombout, J. H. W. M., van den Berg, A. A., van den Berg, C. T. G. A., Witte, P., Egberts, E. (1989b). Immunological importance of the second gut segment of carp. III. Systemic and/ or mucosal immune responses after immunization with soluble or particulate antigen. J. Fish Biol. 35: 179-186

Segner, H., Burkhardt, P., Avila, E. J., Juario, J. V., Storch, V. (1987). Nutrition-related histopathology of the intestine of milkfish Chanos chanos fry. Dis. aquat. Org. 2: 99-107

Stroband, H. W. J., van der Veen, F. H. (1981). The localization of protein absorption during transport of food in the intestine of the grass carp, Ctenopharyngodon idella (Val.). J. exp. Zool. 218: 149-156

Watanabe, Y (1984a). Postembryonic development of intestinal epithelium of masu salmon (Oncorhynchus masou). Bull. Tokoku Reg. Fish. Res. Lab. 46: 1-14

Watanabe, Y. (1984b). An ultrastructural study of intracellular digestion of horseradish peroxidase by the rectal epithelium cells in larvae of a freshwater cottid fish Cottus nozawae. Bull. Jpn Soc. scient. Fish. 50: 409-416

Watanabe, Y., (1984c). Morphological and functional changes in rectal epithelium cells of pond smelt during post embryonic development. Bull. Jpn. Soc. scient. Fish. 50: 805-814

Watanabe, Y., Sawada, N. (1985). Larval development of digestive organs and intestinal absorptive functions in the freshwater goby Chaenogobius annularis. Bull. Tokoku Reg. Fish. Res. Lab. 47-1-10

Manuscript first received: June 29, 1990

Revised version accepted: March 22, 1991 